\title{
RESEARCH TRENDS IN HYPERSPECTRAL IMAGERY DATA
}

\author{
Sujata Alegavi \\ PhD. Research Scholar, Electronics \& Telecommunication Department, \\ Mumbai, India \\ Raghavendra Sedamkar \\ Dean Academic, Thakur College of Engineering \& Technology \\ Mumbai, India
}

\begin{abstract}
Remote sensing and analysis of an object or specific area of the earth at different distances with very large number of bands forms a major part of hyperspectral imaging technology. Currently, a wide range of data sets are obtained continuously from hyperspectral remote sensing, in addition to conventional multispectral remote sensing images, and presented to users by institutions for both commercial and research purposes. These data sets give a vast opportunity to explore number of areas where research can be carried out. Areas such as subpixel mapping, super resolution, target detection, compression and retrieval find a vast scope for research work. However, among all the research topics retrieval forms an important topic for discussion due to large amount of data sets being processed at very small interval of time. Excessiveness of information revealed from these data sets also complicates access of users to images they are interested in. In this study, an in-depth review of current research challenges in Hyperspectral Image retrieval techniques has been done to specify research gaps and trends in this subject.
\end{abstract}

Keywords: Remote Sensing, Hyperspectral Imaging, Hyperspectral Image Retrieval, Subpixel Mapping, Target Detection.

Cite this Article: Sujata Alegavi, Raghavendra Sedamkar, Research Trends in Hyperspectral Imagery Data, International Journal of Computer Engineering and Technology, 10(2), 2019, pp. 67-73.

http://iaeme.com/Home/issue/IJCET?Volume=10\&Issue=2

\section{INTRODUCTION}

Human beings use five senses to adapt themselves with the surrounding world. Some senses require actual touch to feel the things around whereas many senses do not require actual contact with the surrounding. Senses like eyes and ears do not require actual touch to gather information around. We remotely sense things and gather information from the external objects. So we keep on continuously remote sensing objects around us to adapt to our 
surroundings. Thus, remote sensing can be defined as observing or perceiving objects from remote places. We require a medium to transfer information from objects to the sensors. In this case electromagnetic radiation is used as a medium to transfer information from the object to the sensor. An image representing the scene observed forms the output of any remote sensing mechanism. After acquiring the image, analysis of the image and its interpretation forms an important step to extract information from the image. Human visual system is the best example of a remote sensing system in this general sense. The technology of acquiring information about the atmosphere and earth's surface using on board (airborne) or space borne (satellite) sensors is known as remote sensing.

\section{REMOTE SENSING IMAGES}

Various image processing techniques are applied to images that are acquired via remote sensing as these images are digital in nature. Restoration and correction of images is required if the image has been subjected to geometric distortion, blurring or degradation by other factors. Depending on the requirements of the specific problem specific image analysis techniques can be applied. To delineate different areas in an image into thematic classes various image segmentation and classification algorithms are used. Thematic map of the area required is the result of the study. For further analysis and utilization this thematic map can be combined with other databases of the test areas.

\section{HYPERSPECTRAL IMAGES}

Spectral imaging collects and processes information from across the electromagnetic spectrum. In Hyperspectral imaging, the spectrum for each pixel is found in order to identify materials or detect processes.

Red, green and blue are the three primary colors visible to human eyes whereas spectral imaging divides the spectrum into many more bands. Thus the band beyond the visible light forms the base of hyperspectral imaging. The recorded spectra have fine wavelength resolution over a wide range of wavelengths thus providing detailed information about the scene captured. Hyperspectral sensors and processing systems finds wide range of applications in the field of biomedical imaging, geosciences, astronomy, agriculture and physics. A vast portion of electromagnetic spectrum is captured by hyperspectral sensors. There are unique 'fingerprints' associated with certain objects in the electromagnetic spectrum which are known as spectral signatures, these 'fingerprints' are used for identifying various materials of the captured scene. For example, a spectral signature for water body helps geologists find new water bodies in particular inaccessible area.

\section{HYPERSPECTRAL VERSUS MULTISPECTRAL REMOTE SENSING}

Considerable advances in remote sensing technology are driven by environmental issues rapidly arising at regional scales. There is lack of literature on the subject of spaceborne hyperspectral imagery comparison and the assessment of land cover information, specifically in urban areas. By comparing hyperspectral and multispectral imagery, accurate vegetation mapping is possible, especially at dense urban scales. Spectral resolution of hyper spectral imagery and multispectral imagery form the main distinguishing point. Hyperspectral sensors contain bands with narrow wavelengths while multispectral sensors contain bands with broad wavelengths. The advantage of using hyperspectral data over multispectral data is the ability to define surface features with a higher spectral resolution. 


\section{RESEARCH CHALLENGES}

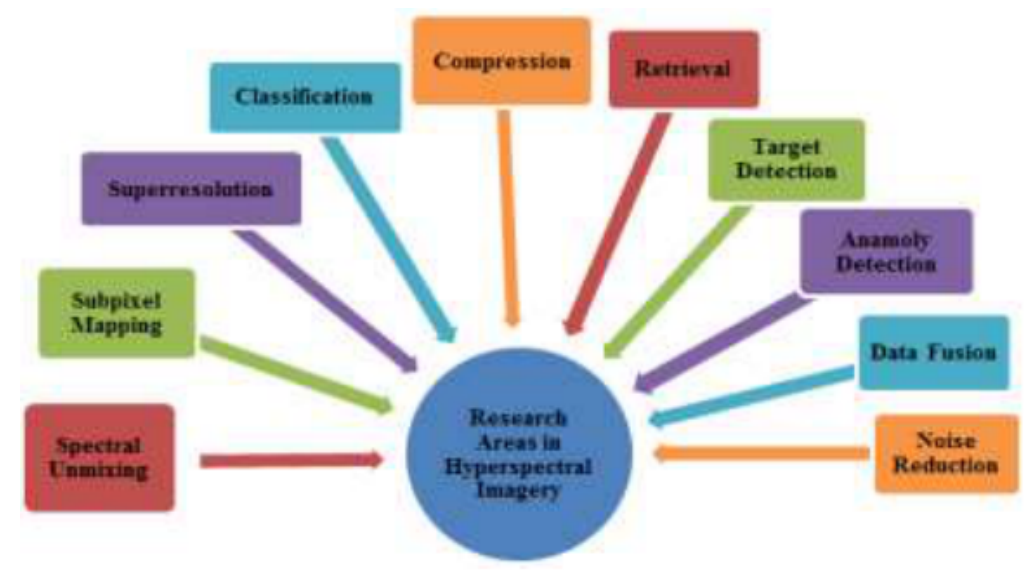

Figure 1 Current research areas in Hyperspectral Imagery.

Ample spectral information is provided by Hyperspectral images to identify and distinguish between unique (spectrally unique) materials. Compared to other remotely sensed data hyperspectral imagery provides detailed information about a particular captured scene which can be further utilized for various other applications. Many multispectral imagers measure reflectance at a few wide wavelength of Earth's surface material separated by spectral segments where no measurements are available. In contrast, most hyperspectral sensors measure reflected radiation as a series of narrow and contiguous wavelength bands. This type of detailed pixel spectrum can provide much more information about a surface than is available in a traditional multispectral pixel spectrum. Although most hyperspectral sensors measure hundreds of bands, it is not the number of measured wavelength bands that qualifies a sensor as hyperspectral but rather the narrowness and contiguous nature of the measurements. A hyperspectral sensor is one that oversamples the phenomena of interest. Because of this, the number and spacing of bands required to qualify a sensor as hyperspectral somewhat depends on the spectral characteristics of the materials under study.

\section{SCOPE OF THE RESEARCH}

Earth observation mining system works on the principle of effective discovery, annotation and retrieval of scenes that are represented. To complete the target mentioned above, numerous techniques should be introduced and combined into EO systems, including image processing, data mining, image retrieval, object recognition and detection, and geographic data management. Among these research domains, image retrieval plays a crucial role. The earlier studies of EO mining adopted the concept of image retrieval based on the metadata of EO products, including geographical location, acquisition time, and sensor type, but the information within the metadata are now insufficient to retrieve interested images, especially when the visual content contains the primary relevant information. Thus, the scope of the research depends on the implementation of the following algorithms for improvement in the retrieval process for earth observation mining application.

- Implementation of retrieval techniques on semantic classification and region based similarity measurement.

- Implementation of retrieval techniques using algorithms for pre-processing image segmentation and feature vector extraction.

- Implementation of algorithms for classification of remotely sensed data. 
- Implementation of multi-label classification and multi-scalable similarity measurement technique for better retrieval.

- Implementation of relevance based feedback using active learning techniques for decreasing the labelling process by the user.

Table 1: Current research areas in Hyperspectral Imagery

\begin{tabular}{|c|c|c|c|c|c|c|}
\hline $\begin{array}{l}\text { Sr. } \\
\text { no. }\end{array}$ & $\begin{array}{l}\text { Current } \\
\text { Research }\end{array}$ & \multicolumn{5}{|c|}{ Research Work Carried } \\
\hline 1 & $\begin{array}{l}\text { Subpixel } \\
\text { Mapping }\end{array}$ & $\begin{array}{l}\text { Sub-Pixel } \\
\text { mapping Based } \\
\text { on a MAP } \\
\text { Model with } \\
\text { Multiple Shifted } \\
\text { Hyperspectral } \\
\text { Imagery: } \\
\text { Utilization of } \\
\text { the } \\
\text { complementary } \\
\text { information in } \\
\text { images which } \\
\text { have sub-pixel } \\
\text { shifts [1] }\end{array}$ & $\begin{array}{l}\text { Attraction } \\
\text { Repulsion } \\
\text { Model-Based } \\
\text { Subpixel } \\
\text { Mapping of } \\
\text { Multi- } \\
\text { /Hyperspectral } \\
\text { Imagery: Use of } \\
\text { spatial } \\
\text { dependence with } \\
\text { attraction } \\
\text { between the } \\
\text { same kinds of } \\
\text { ground objects, } \\
\text { plus repulsion } \\
\text { between } \\
\text { different kinds } \\
\text { of these objects } \\
\text { [2] }\end{array}$ & $\begin{array}{l}\text { Contextual } \\
\text { Subpixel } \\
\text { Mapping of } \\
\text { Hyperspectral } \\
\text { Images } \\
\text { Making Use } \\
\text { of a High } \\
\text { Resolution } \\
\text { Color Image: } \\
\text { Subpixel } \\
\text { mapping that } \\
\text { uses } \\
\text { information } \\
\text { from a high } \\
\text { spatial } \\
\text { resolution } \\
\text { color image } \\
\text { and a lower } \\
\text { spatial } \\
\text { resolution } \\
\text { hyperspectral } \\
\text { image [3] }\end{array}$ & $\begin{array}{l}\text { An Adaptive } \\
\text { Subpixel } \\
\text { Mapping } \\
\text { Method Based } \\
\text { on MAP } \\
\text { Model and } \\
\text { Class } \\
\text { Determination } \\
\text { Strategy for } \\
\text { Hyperspectral } \\
\text { Remote } \\
\text { Sensing } \\
\text { Imagery: From } \\
\text { the } \\
\text { downsampled } \\
\text { original image } \\
\text { or real low } \\
\text { resolution } \\
\text { image, } \\
\text { abundance } \\
\text { images are } \\
\text { obtained by } \\
\text { the spectral } \\
\text { unmixing } \\
\text { method. [4] }\end{array}$ & $\begin{array}{l}\text { Adaptive Sparse } \\
\text { Subpixel } \\
\text { Mapping with a } \\
\text { Total Variation } \\
\text { Model for } \\
\text { Remote Sensing } \\
\text { Imagery: Sparse } \\
\text { representation is } \\
\text { utilized to seek } \\
\text { the optimal } \\
\text { combination of } \\
\text { subpixel patches } \\
\text { for the subpixel } \\
\text { mapping } \\
\text { problem based } \\
\text { on the } \\
\text { preconstructed } \\
\text { DCT dictionary } \\
\text { [5] }\end{array}$ \\
\hline 2 & $\begin{array}{l}\text { Compression } \\
\text { and Retrieval }\end{array}$ & $\begin{array}{l}\text { Highly-Parallel } \\
\text { GPU } \\
\text { Architecture for } \\
\text { Lossy } \\
\text { Hyperspectral } \\
\text { Image } \\
\text { Compression: } \\
\text { High } \\
\text { performance and } \\
\text { very flexible } \\
\text { implementations } \\
\text { can be obtained } \\
\text { when GPUs are } \\
\text { used for satellite } \\
\text { data } \\
\text { compression [6] }\end{array}$ & $\begin{array}{l}\text { A New Digital } \\
\text { Repository for } \\
\text { Hyperspectral } \\
\text { Imagery with } \\
\text { Unmixing- } \\
\text { Based Retrieval } \\
\text { Functionality } \\
\text { Implemented on } \\
\text { GPUs: The } \\
\text { proposed system } \\
\text { is expected to } \\
\text { increase the } \\
\text { value of the data } \\
\text { acquired by } \\
\text { available and } \\
\text { new } \\
\text { airborne/satellite } \\
\text { hyperspectral } \\
\text { imaging } \\
\text { instruments, and } \\
\text { to improve the } \\
\text { availability of } \\
\text { the data and its } \\
\text { associated }\end{array}$ & $\begin{array}{l}\text { Compression } \\
\text { of } \\
\text { Hyperspectral } \\
\text { Images } \\
\text { Containing a } \\
\text { Subpixel } \\
\text { Target: The } \\
\text { goal of this } \\
\text { research is to } \\
\text { compress an } \\
\text { HSI with the } \\
\text { minimal } \\
\text { possible } \\
\text { degradation } \\
\text { of point target } \\
\text { detection } \\
\text { capabilities } \\
\text { [8] }\end{array}$ & $\begin{array}{l}\text { Sparse } \\
\text { Unmixing- } \\
\text { Based Content } \\
\text { Retrieval of } \\
\text { Hyperspectral } \\
\text { Images on } \\
\text { Graphics } \\
\text { Processing } \\
\text { Units: A CBIR } \\
\text { system which } \\
\text { takes } \\
\text { advantage of } \\
\text { sparse } \\
\text { unmixing } \\
\text { techniques for } \\
\text { the process of } \\
\text { cataloging and } \\
\text { retrieving } \\
\text { hyperspectral } \\
\text { scenes from } \\
\text { large } \\
\text { hyperspectral } \\
\text { repositories [9] }\end{array}$ & $\begin{array}{l}\text { Parallel } \\
\text { Hyperspectral } \\
\text { Coded Aperture } \\
\text { for Compressive } \\
\text { Sensing on } \\
\text { GPUs: } \\
\text { Computationally } \\
\text { efficient } \\
\text { implementations } \\
\text { of HYCA and } \\
\text { CHYCA } \\
\text { methods for } \\
\text { hyper-spectral } \\
\text { CS on GPU } \\
\text { platforms [10] }\end{array}$ \\
\hline
\end{tabular}




\begin{tabular}{|c|c|c|c|c|c|c|}
\hline & & & information [7] & & & \\
\hline 3 & $\begin{array}{l}\text { Target } \\
\text { detection }\end{array}$ & $\begin{array}{l}\text { GPU } \\
\text { Implementation } \\
\text { of an Automatic } \\
\text { Target Detection } \\
\text { and } \\
\text { Classification } \\
\text { Algorithm for } \\
\text { Hyperspectral } \\
\text { Image Analysis: } \\
\text { Use of the GPU } \\
\text { architecture } \\
\text { including } \\
\text { considerations } \\
\text { such as the } \\
\text { arrangement of } \\
\text { the data in the } \\
\text { GPU local and } \\
\text { shared } \\
\text { memories in } \\
\text { order to ensure } \\
\text { coalesced } \\
\text { memory } \\
\text { accesses and } \\
\text { low memory- } \\
\text { transfer times } \\
\text { [11] }\end{array}$ & $\begin{array}{l}\text { Hyperspectral } \\
\text { Remote Sensing } \\
\text { Image Subpixel } \\
\text { Target Detection } \\
\text { Based on } \\
\text { Supervised } \\
\text { Metric } \\
\text { Learning: A } \\
\text { supervised } \\
\text { distance } \\
\text { maximization, } \\
\text { which } \\
\text { maximizes the } \\
\text { average distance } \\
\text { between the } \\
\text { positive and } \\
\text { negative } \\
\text { samples [12] }\end{array}$ & $\begin{array}{l}\text { Target } \\
\text { Detection } \\
\text { Based on } \\
\text { Random } \\
\text { Forest Metric } \\
\text { Learning: The } \\
\text { algorithm } \\
\text { utilizes } \\
\text { conventional } \\
\text { relative } \\
\text { position } \\
\text { information } \\
\text { as well as the } \\
\text { absolute } \\
\text { pairwise } \\
\text { position to } \\
\text { learn a } \\
\text { probability } \\
\text { metric that } \\
\text { can add } \\
\text { additional } \\
\text { feature spaces } \\
\text { to better } \\
\text { separate the } \\
\text { desired } \\
\text { targets and } \\
\text { background } \\
\text { [13] }\end{array}$ & $\begin{array}{l}\text { Functions of } \\
\text { Multiple } \\
\text { Instances for } \\
\text { Learning } \\
\text { Target } \\
\text { Signatures: } \\
\text { For } \\
\text { hyperspectral } \\
\text { unmixing and } \\
\text { target } \\
\text { detection } \\
\text { problem, two } \\
\text { algorithms, } \\
\text { convex FUMI } \\
\text { (cFUMI) and } \\
\text { extended } \\
\text { cFUMI } \\
\text { (eFUMI), are } \\
\text { presented in } \\
\text { this paper. [14] }\end{array}$ & $\begin{array}{l}\text { Hierarchical } \\
\text { Suppression } \\
\text { Method for } \\
\text { Hyperspectral } \\
\text { Target } \\
\text { Detection: The } \\
\text { hCEM } \\
\text { algorithm, which } \\
\text { suppresses } \\
\text { undesired } \\
\text { background } \\
\text { spectra and } \\
\text { holds the target } \\
\text { spectra through } \\
\text { a layer-by-layer } \\
\text { filtering } \\
\text { procedure [15] }\end{array}$ \\
\hline
\end{tabular}

\section{TECHNOLOGICAL CONSTRAINTS}

Remotely sensed images carry information about physical parameters in addition to presenting the scene (Earth surface) as matrices of pixels, where each pixel has associated geographical location (latitude and longitude). However, with increase in resolution of optical and synthetic aperture radar (SAR) sensors, pixel sizes have become smaller than the ground objects, enabling automatic object extraction techniques.

Large volumes of data require complicated systems for their analysis, storage and retrieval. To deal with this, users need automated tools to explore and understand the contents of large and highly complex images. For better understanding of images captured via remote sensing or analyzed using image processing there are tools that allow to configure applications solving complex problems of image understanding. However, in reality, the EO data analysis is still performed in a very laborious way at the end of repeated cycles of trial an error, without reaching the desired degree of adaptability and robustness. Also, the existing methodologies are prohibitive for the analysis of large volumes of data and are unable to discover relevant causalities or associations among the objects in the datasets, nor can they reuse information or knowledge set up in other applications. There is a strong need to have environments for development of hybrid algorithms which take into account the diverse nature of remotely sensed images.

\section{CONCLUSION \& RECOMMENDATIONS}

Hyperspectral imaging is widely used way of remote sensing that takes place in various fields. Inherently, hyperspectral imaging sensors reveal excessive information regarding a scene as compared to conventional multispectral remote sensing equipments. Large amount of information can be obtained easily about a particular object or location which provides 
detailed information of the scene. This information can be used for further analysis and applications. There is a wide scope of research that can be carried out in hyperspectral imaging. Mixed pixel problems, noise reduction, target detection, super resolution, compression and retrieval are the areas where research can be carried out. But, the real challenge lies in retrieving meaningful information from large data sets which are created for a particular scene. In this study, a gist of current research topics in the field of hyperspectral imaging is given with an elaborative study on hyperspectral image retrieval techniques.

\section{ACKNOWLEDGEMENTS}

This work is supported in part by NVIDIA GPU grant program. We thank NVIDIA for giving us Titan XP GPU as a grant to carry out our work in deep learning. We also thank the anonymous reviewers for their insightful comments.

\section{REFERENCES}

[1] Xiong Xu, Yanfei Zhong, Liangpei Zhang, Hongyan Zhang, "Sub-Pixel Mapping Based on a MAP Model with Multiple Shifted Hyperspectral Imagery," IEEE Journal of selected topics in applied earth observations and remote sensing, vol. 6, No. 2, pp. 580-593, April 2013

[2] Xiaohua Tong, Xue Zhang, Jie Shan, Huan Xie, Miaolong Liu, "Attraction Repulsion Model-Based Subpixel Mapping of Multi-/Hyperspectral Imagery", IEEE Transactions on geoscience and Remote sensing, Vol. 51, No. 5, pp. 2799-2814, May 2013.

[3] Zahid Mahmood, Muhammad Awais Akhter, Guy Thoonen Paul Scheunders, "Contextual Subpixel Mapping of Hyperspectral Images Making Use of a High Resolution Color Image," IEEE Journal of selected topics in applied earth observations and remote sensing, Vol. 6, No.2, pp.779- 791, April 2013.

[4] Yanfei Zhong, Yunyun Wu, Xiong Xu, Liangoei Zhang, “An Adaptive Subpixel Mapping Method Based on MAP Model and Class Determination Strategy for Hyperspectral Remote Sensing Imagery", IEEE Transactions on Geoscience and Remote Sensing, Vol. 53, No. 3, pp. 1411-1426, March 2015

[5] Ruyi Feng, Yanfei Zhong, Xiong Xu, Liangpei Zhang, "Adaptive Sparse Subpixel Mapping with a Total Variation Model for Remote Sensing Imagery", IEEE Transactions on Geoscience and Remote Sensing, 2016

[6] Lucana Santos, Enrico Magli, Raffaele Vitulli, Jose F. Lopez, Roberto Sarmiento, "Highly Parallel GPU Architecture for Lossy Hyperspectral Image Compression," IEEE Journal of selected topics in applied earth observations and remote sensing, vol. 6, No. 2, pp. 670681, April 2013

[7] Jorge Sevilla, Antonio Plaza, “A New Digital Repository for Hyperspectral Imagery with Unmixing-Based Retrieval Functionality Implemented on GPUs"' IEEE Journal of selected topics in applied earth observations and remote sensing, Vol. 7, No. 6, pp. 22672280, June 2014.

[8] Merav Huber-Lerner, Ofer Hadar, Stanley R. Rotman, Revital Huber-Shalem, "Compression of Hyperspectral Images Containing a Subpixel Target," IEEE Journal of selected topics in applied earth observations and remote sensing, Vol. 7, No.6, pp.22462255, June 2014.

[9] Jorge Sevilla, Luis Ignacio Jiménez, Antonio Plaza, "Sparse Unmixing-Based Content Retrieval of Hyperspectral Images on Graphics Processing Units", IEEE Geoscience and Remote Sensing Letters, Vol. 12, No. 12, pp. 2443-2447, December 2015 
[10] Sergio Bernabé, Gabriel Martín, José M. P. Nascimento, José M. Bioucas-Dias, Antonio Plaza, Vítor Silva, "Parallel Hyperspectral Coded Aperture for Compressive Sensing on GPUs", IEEE Journal of selected topics in applied earth observations and remote sensing, Vol. 9, No. 2, pp. 932-944, February 2016

[11] Sergio Bernabé, Sebastián López, Antonio Plaza, Roberto Sarmiento, "GPU Implementation of an Automatic Target Detection and Classification Algorithm for Hyperspectral Image Analysis", IEEE Geoscience and Remote Sensing Letters, Vol. 10, No. 2, pp. 221-225, March 2013

[12] Lefei Zhang, Liangpei Zhang, Dacheng Tao, Xin Huang, BoDu, "Hyperspectral Remote Sensing Image Subpixel Target Detection Based on Supervised Metric Learning," IEEE transactions on geoscience and remote sensing, Vol. 52, No. 8, pp. 4955-4965, August 2014

[13] Yanni Dong, BoDu, Liangpei Zhang, "Target Detection Based on Random Forest Metric Learning," IEEE journal of selected topics in applied earth observations and remote sensing, Vol. 8, No. 4, pp. 1830-1838, April 2015

[14] Changzhe Jiao, Alina Zare, "Functions of Multiple Instances for Learning Target Signatures" IEEE transactions on geoscience and remote sensing, Vol. 53, No. 8, pp. 4670-4686, August 2015

[15] Zhengxia Zou, Zhenwei Shi, "Hierarchical Suppression Method for Hyperspectral Target Detection", IEEE transactions on geoscience and remote sensing, Vol. 54, No. 1, pp. 330342, January 2016

[16] Licheng Jiao, Xu Tang, Biao Hou, Shuang Wang, "SAR Images Retrieval Based on Semantic Classification and Region-Based Similarity Measure for Earth Observation", IEEE journal of selected topics in applied earth observations and remote sensing, Vol. 8, No. 8, pp. 3876-3891, August 2015.

[17] Begüm Demir, Member, IEEE, and Lorenzo Bruzzone, Fellow, IEEE, “A Novel Active Learning Method in Relevance Feedback for Content-Based Remote Sensing Image Retrieval", IEEE transactions on geoscience and remote sensing, Vol. 53, No. 5, pp. 2323-2334, May 2015.

[18] Jorge Sevilla, Luis Ignacio Jiménez, Antonio Plaza, "Sparse Unmixing-Based Content Retrieval of Hyperspectral Images on Graphics Processing Units", IEEE Geoscience and Remote Sensing Letters, Vol. 12, No. 12, pp. 2443-2447, December 2015.

[19] Miguel Angel Veganzones, Manuel Graña, "A Spectral/Spatial CBIR System for Hyperspectral Images", IEEE journal of selected topics in applied earth observations and remote sensing, Vol. 5, No. 2, pp. 488-500, April 2012.

[20] Begüm Demir, Lorenzo Bruzzone, "Hashing-Based Scalable Remote Sensing Image Search and Retrieval in Large Archives", IEEE transactions on geoscience and remote sensing, Vol. 54, No. 2, pp. 892-904, February 2016. 